\title{
A Espanha dos seus historiadores
}

\author{
The Spain of its historians
}

PASAMAR, Gonzalo. Apologia and Criticism: Historians and the History of Spain, 1500-2000. Hispanic Studies: Culture and Ideas. Bern: Peter Lang, 2010, $291 \mathrm{p}$.

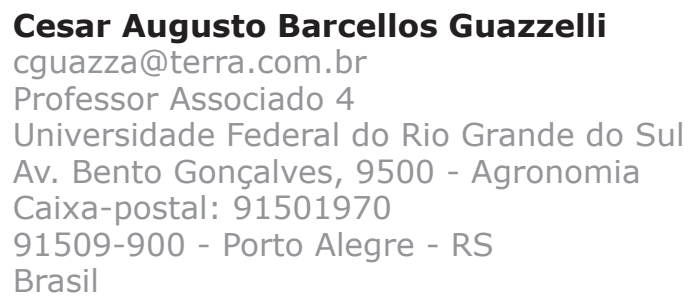

Palavras-chave Historiadores; Historiografia hispano-americana; Identidade nacional.

\section{Keywords}

192 Historians; Spanish-American Historiography; National identity. 
Gonzalo Pasamar é um dos mais renomados especialistas em história da historiografia na Espanha, onde atua como professor na Universidade de Saragoça. Apologia and Criticism é resultado de uma série de palestras por ele ministradas em 2006 no seminário de "Historiadores e Cultura Espanhola nos Séculos XIX e XX", ${ }^{1}$ na Universidade Rutgers, em Newark, Estados Unidos.

Dividida em quatro capítulos, a obra desenvolve-se a partir da constatação de que os estudos sobre a história da historiografia hispânica sempre estiveram separados daqueles dirigidos à identidade espanhola. É precisamente a superação deste hiato que Pasamar pretende promover através do seu livro, em que esses dois campos são reunidos. O livro resultou de mais de 25 anos de pesquisas, e trata da historiografia hispânica em geral. Em razão da maior familiaridade do autor com o período que vai do século XIX ao XX, grande parte das suas atenções dirigem-se para a produção dos últimos 200 anos, terminando com uma análise das últimas décadas, e as perspectivas recentes da Espanha democrática.

O Capítulo 1, "O nascimento da história nacional: de Juan de Mariana a Modesto Lafuente", divide-se em três subcapítulos. "Explorando antecedentes nos séculos XVI e XVII: Juan de Mariana e a tradição das crônicas gerais" é o primeiro deles. Segundo Pasamar, desde o Humanismo e o Barroco já existia, na Espanha, uma "história nacional" baseada nas crônicas. Neste contexto, o jesuíta Juan de Mariana em 1592 publicou uma Historia General de España que já trazia em si traços renascentistas, e que sem se opor às crônicas e privilegiando as grandes linhagens e tradições foi uma obra muito documentada com cartas, discursos e arengas variadas. No século XVI, aponta Pasamar, a obra de Mariana legitimava o Império Espanhol, mesclando-o com a história da Igreja.

O segundo subcapítulo se intitula "Crítica histórica e novos tópicos: a perspectiva iluminista na história da Espanha". Durante os reinados de Carlos III e Carlos IV, afirma Pasamar, buscava-se uma história mais "civil", não restrita aos "grandes homens". Em Madri, Valência e Sevilha os "inovadores", apesar da censura da Igreja, discutiam filosofia e crítica literária e as tensões entre apologia e crítica à Espanha, ou entre Humanismo e Catolicismo eram muito presentes. Pasamar recorda que mesmo com a Inquisição, os espanhóis do século XVIII estudavam Voltaire, Montesquieu, D'Alembert, Diderot, Hume e Smith, e que os "modernos" apropriaram-se da fisiocracia francesa e do liberalismo inglês. Eles abriram suas pesquisas para outros campos, como agricultura, indústria, literatura etc. como mostram alguns exemplos.

O capítulo inicial se encerra com "Compondo uma visão liberal da história da Espanha: Modesto Lafuente e outros historiadores do seu tempo", sobre a primeira geração de historiadores liberais, atuantes também no jornalismo, que se dedicaram a explicar o "nacionalismo" espanhol. O grande expoente desse movimento historiográfico foi, para Pasamar, a Historia General de España de Lafuente, editada em 1850. Essa obra influenciada por pensadores como Vico, Bossouet, Cantú, Michelet, Guizot e Thierry buscava uma "filosofia da história" para compreender melhor o passado.

\footnotetext{
${ }^{1}$ Todas as traduções feitas ao longo da resenha são de minha autoria.
} 
O Capítulo 2, "O caminho espanhol para a profissão histórica: na sombra da regeneração nacional" também é dividido em três partes. O primeiro subcapítulo é "Uma ponte para a profissão histórica: a Academia de História no tempo de Cánovas". Antonio Cánovas del Castillo, historiador ligado à Academia de História, retomou a história nacional desde um viés liberal moderado, que apoiava a Restauração dos Bourbons e teve importante papel na política espanhola. Via na História uma "missão" divina, acima das questões apenas materiais. Assim como ele, os historiadores de seu tempo valorizavam a erudição, mas também o profissionalismo; enfatizavam a análise da documentação, a formação de técnicos e de acervos, preterindo as "filosofias da história" clássicas; favoreciam as monografias e os estudos históricos específicos em detrimento das "grandes histórias".

O segundo subcapítulo "Novas instituições para novos tempos: os começos da historiografia profissional espanhola e a regeneração nacional" inicia-se com a derrota da Espanha na guerra contra os Estados Unidos em 1898. O chamado "Desastre" instigou o movimento "Regeneração". Pasamar recorda que historiadores como Mallada, Macías, Ganivet, Admirall, Prat, Costa e outros, pediam protecionismo às atividades nacionais. Mesmo em pequeno número criaram muitas revistas e entidades, mas o golpe de Primo de Rivera excluiu-os dos cargos acadêmicos por serem conservadores ligados à Igreja. Só na Segunda República um programa de reformas redundaria pela primeira vez na autonomia universitária.

A última parte, "A imagem da história espanhola entre krausismo e 194 positivismo" começa com uma síntese da questão do liberalismo na historiografia espanhola desde o século XVIII. A seguir, Pasamar aborda a filosofia do alemão Karl Krause, que tinha "princípios harmônicos" e buscava "organismos sociais". Os seguidores do "krausismo espanhol" disputavam com os adeptos de Comte os estudos da Sociologia. Alguns autores, como Altamira, defendiam um "krausopositivismo", em que a história política poderia ser vista também como uma história social.

O Capítulo 3 se intitula "Exilados espanhóis restauram a imagem da história: o ensaio histórico e a propaganda", e é dividido em seis partes. O primeiro subcapítulo é "A tradição espanhola dos ensaios históricos e sua importância para a historiografia". Se os historiadores profissionais não optaram pelo ensaio, aferrando-se à "objetividade" das monografias, lembra Pasamar, os ensaístas famosos foram Ortega y Gasset, Unamuno e Pérez de Ayala, que publicavam em jornais. O segundo subcapitulo se intitula "Propaganda totalitária e o ensaio histórico antes e depois da Guerra Civil". Ao final da Guerra Civil, a ditadura franquista impôs seus valores na produção e divulgação da História em todos os níveis, mesmo no ensino fundamental. Neste sentido, as ideias da Falange inspiradas em Nietzche, Spengler, Heidegger, e até Ortega y Gasset - adotaram o conceito de "Hispanidad", atribuindo-Ihe uma continuidade de tradições católicas e da Contrarreforma caras à Espanha Imperial.

O terceiro subcapítulo é "Recuperando o debate cultural: o renascimento de 'O Problema de Espanha' nos anos 1940". Trata da obra de Laín Entralgo, relacionado com vários intelectuais católicos e falangistas. O próprio Ortega y 
Gasset, exilado e criticado pela Falange, voltaria após a derrota do nazi-fascismo em 1945 para apoiar Franco, retomando os estudos teóricos de antes da Guerra. Destacou-se, nesse contexto, também o pensador católico Calvo Serer, que buscou adaptar a Contrarreforma ao presente. A centralidade de Américo Castro é apresentada em "Américo Castro e o Hispanismo Norte-Americano". Os estudos hispânicos tornaram-se importantes nos Estados Unidos durante a Primeira Guerra, devido à importância adquirida pelo Pan-Americanismo. A história espanhola era ainda distante e peculiar. Foi, segundo Pasamar, o trabalho de Castro em Princeton (1940-1953), afinado com o liberalismo americano, que promoveu um grande crescimento da historiografia hispânica dentro dos Estados Unidos. "Uma interpretação filosófica da história da Espanha" mostra a influência de Max Weber no trabalho de Castro, que via na história espanhola a ação de "éticas" de diversas procedências: cristã, muçulmana e judaica. Castro minimizava, assim, as raízes romanas ou visigóticas outrora tão enfatizadas.

O Capítulo 4 é "Historiografia espanhola desde 1950" e divide-se em quatro partes. "O 'Conselho Superior' e a ascensão de Jaume Vicens Vives" enfatiza a importância do Conselho Superior de Investigações Científicas, fundado em 1939 para impor o nacional-catolicismo falangista da Ação Católica e da Opus Dei, sublinhando o controle e a censura por eles exercidos sobre as universidades. O subcapítulo "Construindo uma nova perspectiva na história da Espanha" aborda a obra de Vicens nos anos 1950, quando ainda sob a influência dos Anais, ele buscava analisar todos os grupos sociais em seus cotidianos, meios geográficos, mentalidades, produção material, estatísticas etc. Outros autores aparecem no subcapítulo "A história da Espanha moderna sob o paradigma socioeconômico: os outros pioneiros", em que Pasamar mostra como os estudos socioeconômicos se impuseram até entre falangistas, como no caso do medievalista Ramón Carandes. As pesquisas de Braudel atraiam espanhóis, como seu discípulo Felipe Ruíz Martín, que se tornou tão importante quanto Vicens. Também Antonio Domínguez Ortiz, usava um conceito de classe social com inspiração eclética em Weber, Sombart e Marx; também estudou minorias islâmicas e judias convertidas no século XV. Importante, neste contexto, foi ainda José Antonio Maravall, falangista que depois dos anos 1940 se aproximou do liberalismo. Discípulo de Ortega, ele chegou à história social a partir de influências ecléticas, como Dilthey, Huizinga, Carr, Febvre, Bloch e Braudel.

O último subcapítulo é "Décadas recentes: adaptação a 'Novas Histórias" e aborda o desenvolvimento da História nos 20 anos subsequentes a Franco. Apareceram traduções de hispanistas do americano Raymond Carr e de ingleses: Gerald Brenan, com "O Labirinto Espanhol" de 1943, respondia aos horrores da Guerra Civil; outro, John Elliot, fazia uma interpretação geral do Império Espanhol numa perspectiva comparada. Mas desde Vincens nos anos 1950, a proximidade maior era com a França. Depois da transição, Pasamar sublinha a importância do Marxismo, especialmente através de Josep Fontana, crítico dos Anais, da carência de teoria e do exagero na importância e variedade das fontes e métodos. Já nos anos 1970 e 1980 cresceram perspectivas variadas da história cultural, como estudos de gênero, de minorias marginalizadas, vida cotidiana, micro-história. 
As traduções de obras de Edward Thompson inspiraram histórias do movimento operário, como as de Álvarez Junco e Pérez Ledesma, que negavam a "teleologia marxista". Relações estreitadas com estrangeiros e muitas traduções garantiram uma abrangência de temas da nova história: mentalidades, trabalhadores, movimentos sociais, pobreza, mulheres, história oral, memória, identidade nacional, etc. Também cresceram os estudos historiográficos: além de Fontana, Pasamar cita Julián Casanova, Elena Hérnandez Sandoica, Julio Aróstegui, Miguel Ángel Cabrera, Justo Serna, Anaclet Pons. Ter-se-ia mantido a difusão da história socioeconômica sob a influência marxista e da Escola dos Anais. Ironicamente, na Regressão iniciada em 1996, com o governo José María Aznar do Partido Popular, isto mudou. De acordo com os preceitos do neoliberalismo e seguindo outros conservadores europeus, o presidente espanhol criticou os currículos escolares dos predecessores socialistas, buscando novamente uma centralidade da história "nacional" e a "educação civil".

Cabe destacar que o livro de Gonzalo Pasamar faz um exaustivo panorama de cinco séculos da história da historiografia espanhola. Também conseguiu vincular a produção histórica às concepções identitárias que se construíam na Espanha nas diferentes épocas abordadas, fazendo uma muito adequada correlação texto-contexto, fundamental para a coerência do livro. A importância da temática para estudo e pesquisa de historiadores é muito grande para aqueles que se vinculam a estudos ibero-americanos. Neste sentido, seria mister uma tradução do texto para os idiomas espanhol e português, para uma merecida

196 divulgação do mesmo nos meios acadêmicos latino-americanos. 